\title{
From Subjection to Dispossession: Butler's Recent Performative Thought on Foucault's Latest Work
}

\author{
Elisa Cabrera \\ Universidad de Granada
}

Follow this and additional works at: https://docs.lib.purdue.edu/clcweb

Part of the Arts and Humanities Commons

Dedicated to the dissemination of scholarly and professional information, Purdue University Press selects, develops, and distributes quality resources in several key subject areas for which its parent university is famous, including business, technology, health, veterinary medicine, and other selected disciplines in the humanities and sciences.

CLCWeb: Comparative Literature and Culture, the peer-reviewed, full-text, and open-access learned journal in the humanities and social sciences, publishes new scholarship following tenets of the discipline of comparative literature and the field of cultural studies designated as "comparative cultural studies." Publications in the journal are indexed in the Annual Bibliography of English Language and Literature (Chadwyck-Healey), the Arts and Humanities Citation Index (Thomson Reuters ISI), the Humanities Index (Wilson), Humanities International Complete (EBSCO), the International Bibliography of the Modern Language Association of America, and Scopus (Elsevier). The journal is affiliated with the Purdue University Press monograph series of Books in Comparative Cultural Studies. Contact: <clcweb@purdue.edu>

\section{Recommended Citation}

Cabrera, Elisa. "From Subjection to Dispossession: Butler's Recent Performative Thought on Foucault's Latest Work." CLCWeb: Comparative Literature and Culture 20.4 (2018): <https://doi.org/10.7771/1481-4374.3362>

This text has been double-blind peer reviewed by $2+1$ experts in the field.

The above text, published by Purdue University Press @Purdue University, has been downloaded 151 times as of $11 /$ $07 / 19$.

This document has been made available through Purdue e-Pubs, a service of the Purdue University Libraries. Please contact epubs@purdue.edu for additional information.

This is an Open Access journal. This means that it uses a funding model that does not charge readers or their institutions for access. Readers may freely read, download, copy, distribute, print, search, or link to the full texts of articles. This journal is covered under the CC BY-NC-ND license. 


\title{
PURDUE
}

UNIVERSITY PRESS <http://www.thepress. purdue.edu>

\section{CLCWeb: Comparative Literature and Culture}

ISSN 1481-4374 <http://docs.lib.purdue.edu/clcweb> Purdue University Press @Purdue University

CLCWeb: Comparative Literature and Culture, the peer-reviewed, full-text, and open-access learned journal in the humanities and social sciences, publishes new scholarship following tenets of the discipline of comparative literature and the field of cultural studies designated as "comparative cultural studies." In addition to the publication of articles, the journal publishes review articles of scholarly books and publishes research material in its Library Series. Publications in the journal are indexed in the Annual Bibliography of English Language and Literature (ChadwyckHealey), the Arts and Humanities Citation Index (Thomson Reuters ISI), the Humanities Index (Wilson), Humanities International Complete (EBSCO), the International Bibliography of the Modern Language Association of America, and Scopus (Elsevier). The journal is affiliated with the Purdue University Press monograph series of Books in Comparative Cultural Studies. Contact: <clcweb@purdue.edu>

\author{
Volume 20 Issue 4 (December 2018) Article 8 \\ Elisa Cabrera, \\ "From Subjection to Dispossession: Butler's Recent Performative Thought on Foucault's \\ Latest Work" \\ <http://docs.lib.purdue.edu/clcweb/vol20/iss4/8> \\ Contents of CLCWeb: Comparative Literature and Culture 20.4 (2018) \\ Special Issue Processes of Subjectivation: Biopolitics and Politics of Literature. Ed. Azucena G. Blanco \\ <http://docs.lib.purdue.edu/clcweb/vol20/iss4/>
}

Abstract: In her paper "Between Subjection and Dispossession: Butler's Recent Performative Thought on Foucault's Latest Work," Elisa Cabrera argues that Butler's latest works on public assemblies aim to constitute a collective subject based on vulnerability and interdependence as a guiding principle. This objective is possible, only through the dual action of the subject's dispossession, which implies the loss of recognition within a certain regime of truth on one hand, yet the gain of becoming an interdependent and relational being on the other. To reach this conclusion, this paper will address Michel Foucault's later works on "regimes of truth" On the Government of the living (1980) and the Dartmouth and Berkeley Conferences (1980) and how these lectures, which are centered on the shift of Western subjectivity in primitive Christianity, are interpreted by Butler in a very new sense. This interpretation allows her to develop a new theory on dispossession and collective performativity. 


\section{Elisa CABRERA}

\section{From Subjection to Dispossession: Butler's Recent Performative Thought on Foucault's Latest Work}

In her recent work, the philosopher Judith Butler has continued to consider possible configurations of the political subject. Butler proposes a model that is no longer merely composed of the historic conditions and the regulatory framework, which establish the forms of governmentality concerned with said model, but is also based on a critical investigation of these social conditions that constantly interpellate a community of subjects. Added to this is the process of loss resulting from the critical investigation of the subject who derives from one or another regulatory framework. According to our hypothesis, this notion of critique of oneself as auto-constitution on one hand, and dispossession on the other is derived from the importance that philosophy has placed in recent years on the task of composing a genealogy of western subjectivity; a task that would go on to play a central role in Michel Foucault's work from the 1980s. We must specify that this venture was, according to Foucault's own statements in 1982, the key point that served as the founding meaning in all his work, and not only in the research carried out over the last four years. "My objective [Foucault points out in "The Subject and Power"] has been to create a history of the different modes by which, in our culture, human beings are made subjects (326). In order to do so, Foucault redefines a conceptual tool in "The political function of the intellectual" (1976), the regimes of truth (El origen, 69-70, editors' note, trans. is ours ).

This investigation centers on the hypothesis that, based on such readings and analyses of Foucault's latest proposals in relation to the regimes of truth - the lecture courses and conferences that Foucault delivered during the 1980s, such as the conferences at Dartmouth and Berkeley with the material developed in the course On the Government of the Living - the notions of truth become more relevant in the work of Judith Butler. These notions of truth, from the regimes of truth or veridiction and of truthtelling, therefore make possible a shift from how philosophy understands the process of subjectivation; a process which is, simultaneously, constitutive and dispossessing. With this, so-called "constitutive loss" Butler finds a conceptual tool that enables her to think a collective critical subject when faced with the requisite of the subject's truth-telling, as we intend to demonstrate.

For this reason, Foucault's latest works have become more relevant to the study of subjectivation and political agency of the subjects and collectives; all of which is clearly visible in Butler's latest contributions, in which the processes of subjectivation are developed in a novel way under the prism of dispossession. This being the case, I will dedicate the first part of this article to a brief presentation of the notions that Foucault develops in relation to the regimes of truth and the connection that binds them to hegemony and to the governmentality forms. Additionally, we will compare constituents of the models of Greek, Latin, and Christian subjectivation. This question is central to the lecture courses On the government of the living and The hermeneutics of the subject. Secondly, we will define the conceptual distances that separate the Foucauldian model of subjection and renunciation that originate from the practices of primitive Christianity and Judith Butler's re-reading of these practices in her latest works. With this definition established, we will introduce the figure of dispossession, one that is decisive in our author's considerations. The relationality implicit to dispossession leads to the essay's concluding observation, that is Butler's desire to configure a collective subject based on the core ideas of vulnerability, precariousness and interdependence. This is best exemplified by the activist forms of public assemblies, which the American philosopher has recently paid particular attention to.

The 1980s, the final decade of Foucault's life and oeuvre, marked a of methodological shift in his philosophy which resulted in a series of new elements that have yet to be fully explored. In fact, for the first time in Foucauldian thought, there is an exhaustive explanation of the "regimes of truth" in their ultimate meaning throughout the Collège de France lecture course in 1980, On the Government of the Living, which is still not widely read having only recently being published in French in 2012, in English in 2014, and in Spanish in 2016. This series of lectures forms a working genealogy of the western subject's obedience, which began with the practice of penitence, dating back to the first centuries of Christianity. During this period, the Early Church Fathers did not only develop their religious thought, but they also documented the corporal punishment practices which were progressively instated in the monasteries, forming the basis of western penitence. From his study of Tertuliano and Casiano, amongst others, Foucault concludes that primitive Christianity established "the set of processes and institutions by which, under certain conditions and with certain effects, individuals are bound and obliged to make well-defined truth acts" (On the Government, 94). In other words, a new need arose among individuals to "show how they really are." In this way, Foucault compares this type of demonstration of oneself with the ancient Graeco-latin conscientious, which seeks to assure self-control through an examination of 
actions. Such is the case of Seneca or Pythagoras. Contrarily, in primitive Christianity we discover a more complex relationship with oneself and with others, bound to subjection and to subjectivation, bound to debt and obedience. This bond between the subjection and subjectivation resulted in an asymmetry between what the subject itself produces and represents on the one hand, and on the other, processes by which one's subjectivity is always defined and produced by different techniques of subjection (Cresmonesi et al., Foucault and the Making 2). Through his exhaustive studies of said model of subjectivity introduced through primitive Christianity, Foucault sought to demonstrate the existence of a particular pattern from which the current way of constructing subjectivity derives. This pattern was reproduced, according to Foucault, based on the techniques of confession and behavior control carried out by primitive Christians, and later secularized by means of the modern arts of governmentality: psychiatry apparatus, medicine and judicial power (8) "A transformation - says the Frenchman - which came about at the beginning of the Christian era, the age of Christianity, when the obligation to know oneself became the monastic precept" (Foucault, El origen 46).

We should take into account that, in the first pages of the lecture course, Foucault himself declares a relational shift from his previous analytic framework, the notion of knowledge-power (On the Government 10). This shift is directed towards the existing relationship between the modes of governmentality and the expression of truth. With this shift, in the lecture course of 1980, Foucault restructures his analytic framework and focuses on the processes and the objectives of a particular subject bound to a manifestation of a concrete truth, beginning, as previously mentioned, a new form of analysis of the constitution of the subject that links governmental exercise to a "pure manifestation of truth" (5). In that sense, for Foucault, as he explains, "passing from the notion of knowledge-power to that of government by the truth essentially involves giving a positive and differentiated content to these two terms of knowledge and power" (12). Foucault goes on to identify this action with the Greek word alethourgés, meaning what is true. Yet more importantly, without this expense of truth-telling, power cannot be demonstrated (7). Each demonstration of power we want to analyze comes with a series of practices, of possible procedures to generate a truth, a ritual, to which Foucault attributes the self-coined word aleturgia, derived from alethourgés (7). With this term, Foucault seeks to depict "the set of possible verbal or non-verbal procedures by which one brings to light what is laid down as true as opposed to false" (7). Furthermore, Foucault pauses to reflect on how in classic Greek language, "hegemony" represents "the fact of being in the position of leading others, of driving them and, in a way, their behaviour" (7). And for Foucault, said hegemony seems not to be able to manifest itself with an aleturgia. It is the knot that ties hegemony and aleturgia which allows for the condition of possibility of the "regime of truth," in the interaction between domination techniques and techniques of the self.

In the same year, Foucault announced a series of conferences in Dartmouth and Berkeley on the material studied in On the Government of the Living, in which he would present the conclusions that allowed him to access the readings and to analyze the lecture course. In fact, just as the conferences editors of the first French edition (2013) stated, the philosopher renewed the ideas that were formed and developed in Security, Territory, Population on power techniques and practices of resistance. Quoting the editors, in Foucault "the government is the point of contact whereby the way in which individuals are led by others is expressed in the same way in which they conduct themselves and precisely by means of this definition of the government as an 'unstable balance [...] between the techniques employed in the coercion and processes through which the self is constructed or modified by one's own works', Foucault opens the conceptual space in which he centers his project on a genealogy of the modern western subject (El origen, 22)".

In this way, when we try to form an idea of the way in which a subject is put together, for Foucault it is essential "to consider the instances in which the technologies of domination of some individuals over others calls for processes by means of which the individual acts on themself; and vice versa, the instances in which the techniques of the self are integrated into structures of coercion and domination" (El origen, 45). This is only possible by maintaining close attention to this bond that, on one hand, binds the exercise of power, the leading of others and hegemony, and on the other ties the procedures of truth demonstration and aleturgia; this essential tie between the governing of others, loss, and the possibility that such a loss gives way to the inversion of constituting relationships of power through the other that supports the subjectivity of the rest. Put in another way, "the always-present potentiality of the subjects to alter, unsettle and invent the power relations they are shaped by is not the side effect of techniques of subjection but, on the contrary, their very condition of possibility" (Cresmonesi et al. Foucault and the Making 2).

Previously, we stated that Butler has paid particular attention to the problem of "the truth" and the regimes of truth. Furthermore, and in the same sense, we must highlight that on numerous occasions the Butlerian concept that the "the 'I' has no story of its own that is not also the story of a relation-or 
set of relations - to a set of norms" (Butler, Giving 8), has been attacked with particular critique arguing that such a statement would suggest the incapacity of the subject to exercise or initiate an agency and a moral responsibility (8). Nevertheless, for the philosopher, such a conclusion is deemed invalid in as much that, it is precisely this "dispossession" that can be the founding condition for the start of a social uproar, and even the beginning itself of a criticism although "The ' $\mathrm{I}$ ' is always to some extent dispossessed by the social conditions of its emergence" (8).

Already by the year 2000, Foucault's studies on normative regimes were generating questions for Butler about a subject constituted of these very "formations and delimitations" and of the "stage for action" (Butler, Judith Butler Reader, 306) which presupposes a collective governed by these norms. In her essay "What is Critique? An Essay on Foucault's virtue" Butler suggests that Foucault's probing into the "construction of the self and the poiesis" is the nucleus of a Foucauldian proposal regarding the politics of desubjection: "Paradoxically, self-making and desubjection happen simultaneously when a mode of existence is risked which is unsupported by what he calls the regime of truth (306). In this way, for Butler the construction of the self implies carrying out a criticism when a life form does not become intelligible in the regime of truth whose intention is to continually subjectivize this life form. The critique then, would be that practice which "bring into relief the very framework of evaluation itself" (307). In other words, Foucault's critique is, according to Butler, what allows the subject to realize that they are constituted under a regime of truth on one hand, and to carry out a desubjection from this regime on the other, given that there are always possibilities to alternatively ordering the social life, "and it is from this condition, the tear in the fabric of our epistemological web, that the practice of critique emerges, with the awareness that no discourse is adequate here or that our reigning discourses have produced an impasse" (308).

Previously, in The Psychic Life of Power (1997) Butler was considering the possibility of a "constitutive loss" of the subject (92) whilst the subject becomes aware of its subjection to power and narrates it: "The subject loses itself to tell the story of itself, but in telling the story of itself seeks to give an account of what the narrative function has already made plain" (11). This work lays out the main problems the philosopher will contend with in later decades. These problems include how the subject acts its subjectivity as it is acted upon by power, and how this implies a dispossession of the subject of itself by acting in power: "Power not only acts on a subject but, in a transitive sense, enacts the subject into being. As a condition, power precedes the subject" (13). However, here she hadn't had any contact with Foucault's texts about Regimes of Truth that, from our point of view, were later the key tool that allowed her to think about dispossession as a collective constitutive loss, as we shall see below.

In short, leading up to the year 2000 the politics of truth were already thoroughly integrated in Butler's thought, though it would take another decade to come up with a dispossessed subject in its dual meaning, which we have mentioned, as in the collectivized sense that began to unfold in the 2010 s. This makes us question if it is possible to speak of two moments in the philosophical work of Judith Butler in relation to the constitution of the subject: one more attached to the texts of Foucault, whereby the desubjection marks the contingency and the transformability of the subject, and another, more personal moment in which, based on her works of vulnerability and precariousness, she conceives a dispossessed subject? Butler recovers this "singular sense of poeisis" (Judith Butler Reader 320), of making/constructing/creating the Foucauldian "arts of existence" in order to attribute them with a new plural dimension which would be demonstrated in critical practices and artistic collectives.

This leads us to consider together with Butler: "under what conditions does self-poiesis become a relational category?" (Athanasiou and Butler, Dispossession 67). In Giving an account of oneself (2005), the philosopher's repeated recovery of the regimes of truth appears to be closely related to another of the fundamental concerns of her entire philosophical work on subjectivity, the process of recognition: "the regime of truth offers a framework for the scene of recognition, delineating who will qualify as a subject of recognition and offering available norms for the act of recognition" (22). That is, on the one hand, the regime of truth sets the norms, in relation to which a subject constructs themself, by questioning the very same "self" in relation to such norms. On the other hand, however, the mere existence of this framework does not imply fixity in the understanding it establishes, "deterministically" (22), as Butler would say. But conversely, the fact of being established, with respect to a process, allows one to question and transform the norms that govern understanding in one way or another; "to call into question a regime of truth, where that regime of truth governs subjectivation, is to call into question the truth of myself [...]" (23). In this critique of the norms of recognition, that constitute a self-criticism given that the subject would be constituted by them, and thus derived from the process of selfconstitution, Butler identifies a specific movement of "dispossession": "What price is paid here, when the account that himself he is able to give is indebted to being dominated by others and by their discourse?" (124). In other words, by showing a truth, and doing so by conforming to it, or being 
governed by a certain regime of truth, we leave something along the way: "In Foucault, it seems, there is a price for telling the truth about oneself, precisely because what constitutes the truth will be framed by norms and by specific modes of rationality that emerge historically" (121). This account of oneself, this self-reflection, is never initiated autonomously, but rather with the appearance of an inquiry of the rationality forms established in this regime of truth, which are presented "as an incitement, a form of seduction, an imposition or demand from outside to which one yields" (125). As part of this resignation, which may seem to lead us to a dead-end, the second movement of "dispossession" of the subject comes into play, given that the loss, or the cost, is what transforms the subject into an interdependent and relational being. According to Butler, the subject is used by the norm within a socially established model; the norm uses the me to the same extent that I use it in "a sociability that exceeds me" (36) and:

If it is an account of myself, and it is an accounting to someone, then I am compelled to give the account away, to send it off, to be dispossessed of it at the very moment that I establish it as my account. No account takes place outside the structure of address, even if the addressee remains implicit and unnamed, anonymous and unspecified. The address establishes the account as an account, and so the account is completed only on the occasion when it is effectively exported and expropriated from the domain of what is my own. It is only in dispossession that I can and do give any account of myself. (3637)

Dispossession therefore appears in the form of critical knowledge about ourselves, a "selfquestioning" which does, in fact, put us at risk (38). What is at stake? We risk our ability to be recognised by the regime of truth in which we are immersed, which normatively constitutes our subjectivity, the possibility of recognition as valid subjects within the regime, within the intelligibility framework. However, in Foucault, the author notes, "the price is the suspension of the critical relation to the truth regime in which we live (Butler, Giving an account 122). In other words, would we lose our critical capacity, 'our critical relation' with the truth, to manifest this truth under a set normalizing regime to which we should adjust in order to comply with its requisites? Here we discover a fundamental point of divergence between our two authors; while Foucault reveals the loss of the critical relation on having to "adapt" to the regime, Butler shows this loss to be the gain of the critical relation in the discussion on the truth itself as something that does not adapt to the regime of truth.

It is by no means accidental that we use the term "framework" as a concept that is homologous with the regime of truth. In 2009, Butler published Frames of War, a title in which she uses the notion of "framework" to refer to the regimes of truth that are established in war zones, which deny certain precarious lives within this framework the recognition of subjectivity, in as much that the purpose of the framework "is, clearly, to outline the sphere of appearance itself" (1), that is, to confine the recognition. Frames of War centers its analysis on the precarious body as a deconstructive tool of agency. Just as for Butler, "the body is exposed to socially and politically articulated forces as well as to claims of sociality [...] that make the body's persisting and flourishing possible" (3), the vulnerability of the body -making it something precarious, in the sense of fragility and instability - is what attributes it with agency, but also with responsibility for the rest of the vulnerable bodies in relation to its own: "Precariousness implies living socially, that is, the fact that one's life is always, in a sense, in the hands of the other" (14). Further, when we are faced with social systems that strengthen models of "responsibilization" that appeal for a process of production for self-sufficient individuals (60), Butler's proposal opens itself up to a "responsibilization" in an opposing sense. Faced with regimes of truth that call for individuation more and more, only one proposal that centers on the "we" as a vulnerable subject would be capable of deconstructing the framework of intelligibility that the regimes of truth, from the current post-Fordist model of production, instate. Such reflections, along with Butler, bring into question: "how we might rethink the 'we' in global terms in ways that counter the politics of imposition"? (Frames 38).

On the basis of this search as a premise, the philosopher develops her subsequent works placing the interrelational subject in a central position. In Dispossession, her published conversations with the Greek philosopher Athena Altanasiou, Butler instigates with the hypothesis that the movement of subject dispossession is what permits both recognition and agency. It is dispossession that makes possible the encounter with otherness by revealing the limits of the self-sufficient subject and showing the dispossessed subject to be vulnerable. Thus, we can see how, on the one hand, dispossession grants agency to the interdependent subject yet on the other it makes the subject vulnerable when put up against a normalizing regime of truth. Despite the phrase making vulnerable seeming to be something undesirable, it is precisely this notion that allows the philosopher to constitute a new model of collective political subjectivity. The authors problematize this seemingly disjunctive space in which the performativity of the norms that establish the regimes of truth produces and models us based on the 
same norms. However, on the contrary, "the possibility of critical invocation and resignification of the normalized order remains open" (127). In fact, the philosopher believes that sociability can be understood under this "equation" in two ways, "First, the norms against which we struggle are social norms, and they govern us precisely as social creatures. Second, we make ourselves, if we do, with others, and only on the condition that there are forms of collectivity that are struggling against the norms in similar or convergent ways" (67).

In this sense, Butler returns her attention to Foucault and to self-care, which is understood as a form of poiesis (69). Thus, this poietic "self" which acts despite being fully aware of the loss that such acting, or self-recognition entails, invades the framework of intelligibility - such "general historical schema or schemas that establish spheres of the intelligible" (Frames 6) - in order to start to deconstruct it, revealing a new space for manifestation and reclaiming a new regime of recognition: "The 'I' articulated, claimed or defended by those dispossessed of self-determination - those constituted as an impropriety - bears the burden and the responsibility of injurious and unjust genealogies alongside its aspirations to freedom" (Dispossession 99). Once again, we come across the double figure of dispossession in terms of relationability, in terms of avowal. "Avowal is a scene of address" [added emphasis] ("Wrongdoing" 84), a scene in which new narratives are possible and desirable.

At this stage, one might question: What role do the primitive Christian practices of exomologesis play in this critical task? In what way are the Christian practices of exomologesis important to Butler? Undoubtedly, we believe they are important in a performative sense. Let us return for a moment to Giving an account of oneself. Butler suggests practicing, according to the terms put forward by Foucault relating to the constitution of the subject during primitive Christianity, a contemporary "reconsideration" of said subject or perhaps, of the potentiality that this constituting loss harbors "so [Foucault] turns to confession to show how the subject must relinquish itself in and through the manifestation of the self it constructs. In this sense, the manifestation of the self dissolves its interiority and reconstitutes it in its externality" (113). This was, ultimately, the aim of the Foucauldian investigation that began round the year 1980; that is, trying to comprehend the shift inferred by the Christian practices of the self and the way in which these practices become the institutional normality under what today constitutes the contemporary subjects.

According to Casiano in Institutions cénobitiques "the Christian self-examination is no longer applied to the acts, as was the case in ancient Greek Roman history, but rather to a 'previous' command which - and this is a radical innovation - is constituted as a 'field of objective data that requires interpretation'" (Foucault, El origen 29), the "control of thoughts" and "the revelation of the truth about oneself can never be separated from the obligation of sacrificing the self" (31). In other words, for Foucault, Western subjectivity can be traced back to a movement of self-resignation, of loss, of subjection. During the seminar in Berkeley, Foucault asks: "What is this obligation of truth-telling in relation to oneself that was imposed on everyone including mad people, if they want to become reasonable and normal?" (40). Having analyzed Butler's focus, we have reformulated the question: In what way were the practices of alethurgy instated in the West as a sine qua non condition in order to generate recognition of part of the regime of truth? We believe that this reformulated question can act as a fundamental nucleus in both the latest of Butler and Foucault's works, considering that for Foucault "this project strives to reveal the moment in which such practices become coherent and reflexive techniques with defined objectives, the moment in which a particular discourse breaks away from the techniques and ends up being accepted as true, the moment in which the practices are bound to the obligation of searching for the truth and telling the truth" (43).

We can therefore appreciate two truths in Foucault; the truth as a force developed in the Greek Latin culture, and the truth as a regime, consolidated throughout the first two centuries of Christianity. In Berkeley, Foucault precisely described this form of truth which is brought about, or is expressed as a force on describing the advice that Seneca offered his disciple Sereno: "This addition to the already known is not knowledge, it is a force; a force capable of transforming pure knowledge and simple consciousness into a true way of life" (El origen 55). In the Greek Latin period, we discover a type of subject that experiences the truth, not by discovering it in oneself, but rather by practicing it, and constituting it (56). For their part, the Christian practices of the self instigate a hermeneutic process that seeks to reveal the darkest secrets of subjectivity. There is no will for the truth, but rather decoding of the truth. For Foucault, in this very instance, we are dealing with an inedited from, one of extraction.

And yet, it is in this extraction carried out by the Christian practices of the self that establish, as it were, modern subjectivity, that Butler finds a place for expression; an extraction that demonstrates itself, and which is executed through exomologesis, by means of a corporal performative act that puts the extracted truth in action. Therefore, by "reconsideration" Butler means jeopardizing the intelligibility and challenging the social convention based, precisely, on this ecstatic movement, "one that moves me 
outside of myself into a sphere in which I am dispossessed of myself and constituted as a subject at the same time" (Giving an account 115). What's more, Butler adds, "The sinner does not have to give an account that corresponds to events but only make himself manifest as a sinner. Thus a certain performative production of the subject within established public conventions is required of the confessing subject and constitutes the aim of confession itself" (113).

In the performativity that puts its body into action, in the practice of exomologesis, as previously mentioned, "the manifestation of the self dissolves its inwardness and reconstitutes it in its externality" (113). This practice of exomologesis is always external to the subject, it is always expressed for the behalf of someone else, in front of someone else; we could say it becomes public. As we move forward, such exteriority, and making ourselves public, puts us at risk and puts our recognition at risk, and makes us vulnerable much like interdependent subjects and subjects relationally constituted. We might say, we share "a plural bodily life" (Dispossession 196), a "plural performativity" (175), and we find that our bodies are, precisely, "a turbulent performative occasion" (178). So, if we understand precariousness as Butler does, the only way to prevent the risk of the loss of recognition resulting from constituting oneself externally for the first time, is by constituting oneself in a way that collectively involves others, through whom, the subject sees themself constituted, understanding the role of the body as plural practice. This plural practice does not fall on deaf ears, it is constituted as living memory. In order to give an example of this body composed of common memory, Butler draws attention to the Guatemalan performer Regina José Galindo and her piece Quién puede borrar las huellas:

In that most impressive piece of 2003, Galindo protested the decision of the Guatemalan Supreme Court to allow the presidential candidacy of Efraín Ríoss Montt, a former member of the military junta known for his participation in political murders. The piece commences with Galindo in a black dress carrying a white basin filled with blood through the streets of Guatemala City. She occasionally sets the basin down, dips her feet in the blood, drawing the attention of pedestrians, and then continues her processional leaving the traces of blood as she goes. The walk ends at the steps of the National Palace, the site where the military dictators ruled, where, confronted by a police line blocking entry into the building, she sets down the basin in front of them, dips her feet for the last time, and leaves them face to face with two bold footprints of blood (169).

In this type of political regime there is an institutional regulation of the truth, as is the case of postwar Guatemala. During this regime, Galindo unleashed a new reconciliation with the truth, which the governing regime of truth intended to be forgotten. The example of Galindo's performative power of representation acts collectively, externalizing the truth through use of the body and recovering the power of the representation of public pain. It is not about a sobering thought for the rest "who don't know," but rather an incarnation of the victims through memory, a way of sharing a knowledge that gives rise to a new form of intelligibility towards what is real, what is political. With Galindo, we can observe how Butler's model of public appearance, and in her performative thought, that contemplates the body as "a memory come alive" (172) is reminiscent of the Christian exomologesis: "the body suffers, falls, and is constrained and overwhelmed by external force, the performing body also persists, survives, showing and enacting a social history, memorializing those forms of suffering and loss against the lure of forgetfulness" (170). The exomologetic practice invades the regime of truth, deconstructing it and allowing access to a truth that the regime continues to deny, just like the case of Guatemala's historical memory of the military dictatorship. The truth is externalized in the body.

Performative externalization or revelation is expressed intensely according to our author in the figure of the controversial assembly, which she dedicates one of her most recent works to. With Notes Toward a Performative Theory of Assembly (2015), Butler wishes to express a theory of the political body that merges with the category of the vulnerable body. For Butler, there is no escape from vulnerability that implies appearance in the world and thus "it is not altogether right to conceive of individual bodies as completely distinct from one another" (130) and "The conditions of support for the most vulnerable moments of life are themselves vulnerable" (131). For this reason, she considers that the vulnerability of the body is what transforms it into "the means and ends of politics" (129), given that it is the characteristic that leads us to engage with what is beyond us, "it is opening ourselves up when faced with the body of another" (149). It is what makes us interdependent on each other. As a result, "Each 'I' brings with it the 'we' (51). Throughout the development of Notes Toward a Performative Theory of Assembly we can observe how Butler returns to the Foucauldian concept of "regimes of truth" in order to refer to the appearance frameworks of the social movements in which, according to Butler, the collective subject is materialized in a more dynamic way. As in Giving an account, the use of Foucauldian terminology stems from an interest in the appearance and performance of the body in the framework or regime as a constructor of subjectivity; in other words, an interest in performativity of the body in an exomologetic sense. 
On the other hand, Butler's critique of Giorgio Agamben's "bare life" concept demonstrates the dispossession's necessary double movement and foreclosure of any political agency: "Are we going to say that those who are excluded are simply unreal, disappeared, or that they have no being at all? Are they mere life or bare life? [...] If we do that, we not only adopt the position of a particular regime of appearance but ratify that perspective" (Notes 78). The conception of human life as "bare life" would ultimately deny these subjects' capacity to congregate and resist and, therefore, to access a new space of revelation from which new frames of recognition are possible. If this were not the case, how could we realize or recognize the forms of agency and resistance of the dispossessed? The dispossessed subject, far from being a "bare life," and being outside of the political sphere, is the one who is aware of and affirms the different social ties they are constituted of, who knows themself to be vulnerable and who, on becoming aware of themself, searches within 'us' for what they have been dispossessed of. Far from being a mere existence, normally it is "angered, indignant, rising up, and resisting" life (80), that is collectivized and searches for "ways of caring for one another or establishing networks of support" (80) in the rest of the dispossessed. They are not the same, nor should we confuse the bare life or life without agency with the precariousness that life implicitly entails and the dependency that derives from this. It is the framework of intelligibility that dictates the extent of precariousness a life can reach. Thus if "precariousness implies living socially" (Frames 14), and if "survival is dependent on what we might call a social network of hands" (14), it is the understanding of precariousness that offers the first framework open to the possibility of a collective subject. The fact that a life finds itself in a situation of extreme precariousness, does not mean that it has become a bare life, removed from history and with no possibility of escape or change. What it does mean, however, is that the life must reclaim the conditions that make it "livable." Such a claim constitutes political and ethical responsibility that, for Butler, can only be undertaken collectively.

Lastly, we cannot fail to mention that the influence of the philosopher Etienne Balibar, in paricular his notion of citoyenneté imparfaite (imperfect citizenship), which echoes in the Butlerian proposal of the assembly as a deconstruction of institutional recognition. An "imperfect citizenship," in the words of Balibar, is defined by the extent to which it is and will be in permanent reformation. The institutionalized citizenship is thus faced with a threat which implies the very potential of the power of which it is formed, "the 'insurrectional' power of political movements that aim to conquer rights that do not yet exist" (Balibar, Citizenship 37). Butler goes on to analyze the forms of revelation of this 'us', conscious of its interdependence since the assented political protests in the assemblies. For Butler, the assemblies represent said "plural and public action is the exercise of the right to place and belonging to the community" (Notes 59-60). Based on the exercise of this right, the "us" is creating the right to an appearance that was otherwise denied. Butler always considers this invasion in the right for appearance in relation to the body "when the body 'speaks' politically" she says, "it is not only in vocal or written language" (83), but in its own exhibition, it implies a rupture of the regime of legitimate appearance, and the body will do so through a specific performativity. Shared body language, literal physical union in the protest of holding hands, embracing or being knocked down or beaten etc. are among the physical practices that Butler through exomologesis. For her, such practices put a new regime of truth into action before the demand for recognition and dispute existing forms of political legitimacy from the scene of truth.

Through this vindication of the appearance of the assembly in the public space as a performative exercise of recognition, Butler, via Foucauldian self-constitution, invests in a subject that, rather than express or manifest "I am, I see, I do," instead expresses an 'us' that, in common, refutes and voids the previously existing forms of political legitimacy. If indeed Foucault considers the constituting Christian loss as a regression that impedes or hinders agency, the process which Butler will follow by means of dispossession would involve returning agency to this constituting loss from which we can no longer detach ourselves. And this takes places because the loss is precisely what constitutes the subject with another, toward another, externally to themself. The controversial assembly, the protest in the street whereby we are subjugated and submitted, is the constitutive space where we are conscious of dispossession, of the constitutive loss which, when with others both implicates and imposes. Butler proposes an ethical agency project of 'my body' and the body of others, whose objective will be the conformation of a co-responsible, collective movement that, with its common performative presence in the public space, shapes the yearning collective subject. However, in honor of the Foucauldian critique, Butler finds one of the tools that would enable the conformation of a collective and controversial subject. The critique is "a means for a future or a truth that it will not know nor happen to be, it oversees a domain it would not want to police and is unable to regulate" (Judith Butler Reader, 308). 


\section{Works cited}

Athanasiou, Athena and Judith Butler. Dispossession: The Performative in the Political. Polity, 2013.

Balibar, Etienne. Citizenship. Polity, 2015.

Butler, Judith. The psychic Life of Power. Theories in Subjection. Stanford UP, 1997.

---. Giving an account of oneself. Fodham UP, 2005.

---. Frames of war. When Is Life Grievable?. Verso, 2009.

---. Notes Toward a Performative Theory of Assembly. Harvard UP, 2015

---. "Wrong-Doing, Truth-Telling: The Case of Sexual Avowal." Foucault and the Making Subjects, edited by Cresmonesi, Laura, Orazio Irrera, Daniele Lorenzini and Martina Tazzioli, Rowman \& Littlefield International, 2016, pp. 75-93.

Butler, Judith and Salih, Sara. "What is Critique? An essay on Foucault's virtue." The Judith Butler Reader, Blackwell, 2004.

Cresmonesi, Laura, Orazio Irrera, Daniele Lorenzini and Martina Tazzioli, eds. Foucault and the Making Subjects. Rowman \& Littlefield International, 2016.

Foucault, Michel. "The subject and Power". Essential works of Michel Foucault. Volume III, Power. Edited by Paul Rabinow, The New York Press, 1998, pp. 326-348.

---. "La foction politique de l'intellectuel" (The Political Function of the Intellectual). Dits et ecrits III, Gallimard, 1994 pp. 109-114.

---. On the Government of the Living: Lectures at the Collège de France 1979-1980. Palgrave Macmillan, 2014.

---. El origen de la hermenéutica de sí. Conferencias de Dartmouth, 1980 (The Origin of the Hermeneutics of the Self. Darthmouth Conferences, 1980), Siglo XXI, 2016.

Author's profile: Elisa Cabrera is research staff in Universidad de Granada with a grant of the Ministery of Education, Culture and Sports of Spain. She teaches Aesthetic Thought and Contemporary Art History. Her main lines of research are the study of the concept of "feminicide" in contemporary artistic practices and feminist activist movements of the present day, among others. She has published "'The Part About the Crimes' in 2666: visibilizing 'femicide' as Politics of Literature" (2016) and "Nothing to Say, Only to Show. Gender and Colonialism in Hannah Höch's photomontage" (2017). She is also a member of the research project "Processes of subjectivation: biopolitics and politics of literature. The legacy of the last Foucault." Email: <elisacabrera@ugr.es> 